and $1940 \mathrm{~s}$ is now described as a 'second darwinian revolution'.

Mayr's emphasis on the nondarwinian character of most latenineteenth-century evolutionism is important, although we can perhaps forgive him for spending more time on those who did accept natural selection (for example, August Weismann) than on those who did not. He is surely correct in his claim that much of the enthusiasm for nondarwinian mechanisms such as lamarckism and saltationism was generated by a desire to retain as much as possible of the old philosophies of teleology and essentialism.

Mayr's claim that Darwin was successful in promoting the theory of common descent is not as clear-cut as he would have us believe. The early darwinians accepted that 'related' species possess similar characteristics because they are descended from a common ancestor. Most lamarckians and supporters of orthogenesis (directed evolution) challenged this interpretation of 'relationship'. They invoked both adaptive convergence and nonadaptive trends to argue that similar characters can be developed indepen-

\section{Meddling with intent} John Durant

The Art of Scientific Rhetoric. Edited by Marcello Pera and William R. Shea. Science History Publications/USA, Box 493, Canton, Massachusetts 02021: 1991. Pp. 212. \$39.95.

IT has recently become fashionable to subject scientific texts to rhetorical analysis. To many scientists, this seems subversive. As Gerald Holton points out in his contribution to this volume of essays, practitioners of modern science claim to use an 'objective' method of demonstrating how nature works; and they oppose in principle all modes of persuasion that rely on subjective factors such as the personal characteristics of individual scientists. Thus, in a draft preamble to the original statutes of the Royal Society of London, Robert Hooke asserted that scientists did not intend to 'meddle' with 'rhetoric'.

What, then, is the point of talking about scientific rhetoric? For some analysts, the point is precisely to prick the bubble of scientific objectivity. For them, the demonstration that science is rhetorical is taken to show that science is not a strictly rational enterprise, or even that science provides no genuinely objective knowledge of the world at all. On

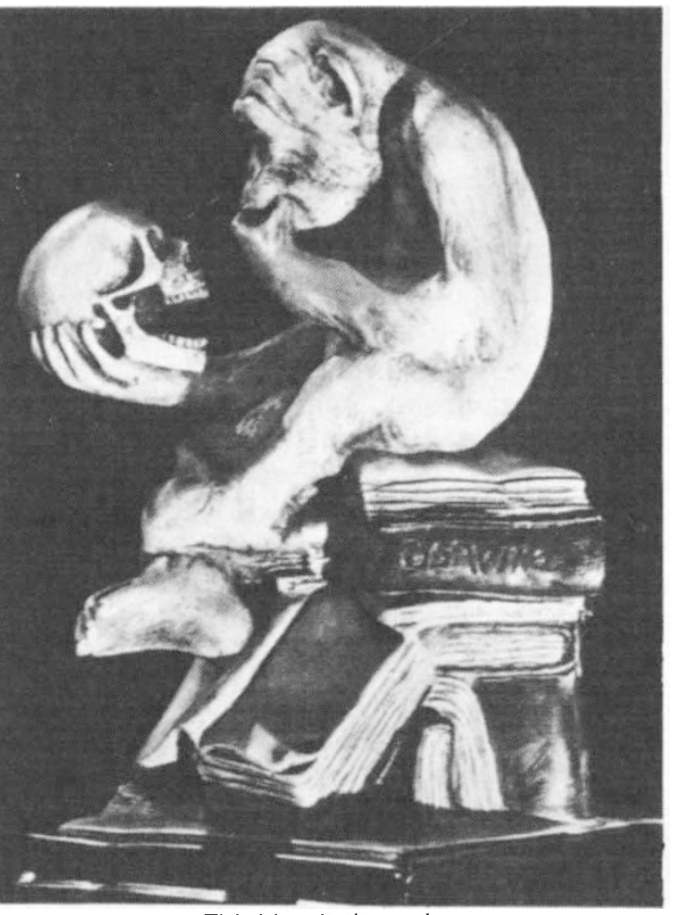

past, their approach undermined the value of the theory of common descent for tracing phylogenies. This view of evolution was also part of a campaign to retain more traditional values, as can be seen in the efforts made by many early palaeoanthropologists to distance the human race from the apes. By concentrating on ideas about the evolutionary mechanism, Mayr has missed an important point that can be revealed only by looking at how the idea of evolution was actually used to reconstruct the history of life on Earth.

Mayr ends by outlining his views on the most recent developments in evolutionary theory. He is convinced that important steps have yet to be taken, but equally convinced that these steps will take off from the foundation already established. Mayr can hardly be counted as an impartial judge of darwinism's role in the development of evolutionism, but it is valuable to have his "mature reflections" expressed so concisely and elegantly.

dently in widely separated lines of descent. Although proponents of this idea did not deny that the lines linked up if they are traced far enough back into the

Peter J. Bowler is in the Department of Social Anthropology, The Queen's University of Belfast, Belfast BT7 $1 \mathrm{NN}$, UK.

this view, scientific truth is exposed as merely the sum of all those things that scientists have persuaded themselves to believe.

This is obviously silly. If rhetoric and logic are set up as rival explanations for the vast corpus of scientific knowledge then logic wins easily. Scientific knowledge may be partial, and it may be provisional; but it certainly is not an arbitrary rag-bag of all the propositions that a professional community of scientific rhetoricians has taken to its bosom

Instead of opposing rhetoric with logic, most of the essays in this volume take the far more sensible view that the two play complementary roles in science. In the words of the editors, "The central question . . . is not whether science gives us genuine knowledge but how it justifies the knowledge that it acquires, transforms and disseminates".

There are two related features of science that make rhetoric an essential part of this process of justification. First, science is not produced solely in a twoway encounter between nature and the individual scientist; rather, it is produced in a three-way encounter between nature, the individual scientist and the community of research colleagues. Scientists are obliged to convince their professional colleagues of the validity of their findings; this obliges them to provide written accounts of what they do.

Second, there is no completely rigorous system of scientific thought. In other words, there is no formal algorithm whereby evidence may be translated into discoveries. In Karl Popper's terms, science is conjectural; and this means that accounts of scientific research contain more than syllogisms. Typically, what they contain are arguments in favour of particular interpretations of the available evidence.

The twin facts that science involves obtaining the assent of others and that it is conjectural make persuasion inescapable. As Richard Westfall observes, there is a world of difference between Galileo's scornful invective against the scholastics and Newton's icy disdain for both his forebears and his critics; but in their different ways, each man defined, addressed and won over a particular audience to their point of view. Each man was skilled in both logic and rhetoric. The essays in this volume provide a useful guide to the rhetorical devices that scientists have found useful in their work.

Sir Peter Medawar once famously observed that we should not be deceived by the strict conventions of the scientific paper. Beneath the calm surface, there are deep currents of rhetorical intent. This fact should not be taken as evidence that science is imperfect, or that its claims to objectivity are bogus. Rather, it should be taken as an important aspect of the enterprise by which we gain a better understanding of the world.

John Durant is at the Science Museum Library, Exhibition Road, London SW7 $5 \mathrm{NH}$, UK. 